\title{
高寒草甸退化过程中群落生产力和物种多样性的 非线性响应机制研究
}

\author{
陈 宁 ${ }^{1,2}$ 张扬建 $1,3,4$ 朱军涛 $1^{*}$ 李军祥 ${ }^{5}$ 刘瑶杰 ${ }^{1,2}$ 组佳星 ${ }^{1,2}$ 丛 楠 ${ }^{1}$ \\ 黄 珂 ${ }^{1}$ 王 荔 ${ }^{5}$
}

${ }^{1}$ 中国科学院地理科学与资源研究所, 生态系统网络观测与模拟重点实验室, 拉萨高原生态试验站, 北京 $100101 ;{ }^{2}$ 中国科学院大学, 北京 $100190 ;{ }^{3}$ 中

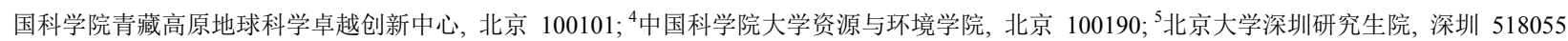

摘 要 为了阐释青藏高原高寒草甸退化的关键生态过程, 该研究依托藏北高原草地生态系统研究站(那曲站), 设置不同退 化梯度实验, 即对照、轻度退化、中度退化、重度退化和极度退化 5 个梯度, 探究群落生产力和物种多样性对不同退化强度的 响应机制。结果表明: 1)随着退化程度不断加剧, 地上生物量呈现线性或非线性增加趋势, 在重度退化处理下, 地上生物量显 著高于对照 $32.3 \%$, 其中高山嵩草(Kobresia pygmaea)地上生物量呈非线性下降趋势, 而矮火线草(Leontopodium nanum)地上 生物量呈非线性增加趋势; 2)与地上生物量的响应模式相反, 随着退化程度加剧, 地下生物量与总生物量均呈现非线性降低 趋势; 3)高寒草甸退化过程中, 物种辛普森指数、丰富度指数、香农多样性指数和均匀度指数均呈现非线性上升趋势。结构 等式方程结果表明, 土壤碳含量和体积含水量与地下生物量均呈现显著的正相关关系。土壤碳含量、体积含水量和砾石质量 比对地上生物量无显著影响, 土壤碳、氮含量与物种多样性指数呈现显著的负相关关系。研究认为地上生产力的变化不能很 好地指示草地的退化程度, 建议今后研究应以可食性牧草和毒杂草等植物功能群的变化来衡量草地退化。

关键词 高寒草甸; 退化梯度; 物种多样性; 生产力; 非线性响应

陈宁, 张扬建, 朱军涛, 李军祥, 刘瑶杰, 㸖佳星, 丛楠, 黄珂, 王荔 (2018). 高寒草甸退化过程中群落生产力和物种多样性的非线性响应机制研究. 植物生态学报, 42, 50-65. DOI: 10.17521/cjpe.2017.0252

\section{Nonlinear responses of productivity and diversity of alpine meadow communities to deg- radation}

CHEN Ning ${ }^{1,2}$, ZHANG Yang-Jian ${ }^{1,3,4}$, ZHU Jun-Tao ${ }^{1 *}$, LI Jun-Xiang ${ }^{5}$, LIU Yao-Jie ${ }^{1,2}$, ZU Jia-Xing ${ }^{1,2}$, CONG Nan ${ }^{1}$, HUANG $\mathrm{Ke}^{1}$, and WANG $\mathrm{Li}^{\mathrm{5}}$

${ }^{1}$ Lhasa Plateau Ecosystem Research Station, Key Laboratory of Ecosystem Network Observation and Modeling, Institute of Geographic Sciences and Natural Resources Research, Chinese Academy of Sciences, Beijing 100101 China; ${ }^{2}$ University of Chinese Academy of Sciences, Beijing 100190 , China; ${ }^{3}$ CAS Center for Excellence in Tibetan Plateau Earth Sciences, Beijing 100101, China; ${ }^{4}$ College of Resources and Environment, University of Chinese Academy of Sciences, Beijing 100190, China; and ${ }^{5}$ Peking University Shenzhen Graduate School, Shenzhen 518055, China

\footnotetext{
Abstract

Aims The alpine meadow degradation could have profound effects on the grassland productivity. The aim of our study is to clarify the dynamic response of community productivity and species diversity in the process of alpine meadow degradation.

Methods In the Institute of Geographic Sciences and Natural Resources Research, Chinese Academy of Sciences, Northern Tibetan Grassland Ecosystem Research Station (Nagqu station), we conducted stages experiments with multiple degradation levels: control, mild degraded meadow, moderate degraded meadow, severe degraded meadow and serious sandy meadow.

Important findings The response of aboveground biomass to alpine meadow degradation showed a linear or nonlinear increased response patterns, but the belowground biomass and total biomass decreased nonlinearly. As observed in measurement of aboveground biomass, Margalef index, Simpson index, Shannon-Wiener index and Pielou evenness index also exhibit a nonlinear increased response to degradation. The results of structural

收稿日期Received: 2017-10-09 接受日期Accepted: 2018-01-04

基金项目：国家重点研发计划(2016YFC0501802和2017YFA0604802)和国家自然科学基金(41571195和41501103)。Supported by the National Key Research and Development Project of China (2016YFC0501802 and 2017YFA0604802) and the National Natural Science Foundation of China (41571195 and 41501103).

* 通信作者Corresponding author (zhujt@igsnrr.ac.cn)
} 
equation models showed that belowground biomass has a positive relationship with soil carbon content $(p<$ $0.05)$ and volume water content $(p<0.1)$. However, soil nutrient and soil physical properties had no significant impact on aboveground biomass $(p<0.1)$. Compared with soil physical properties, soil nutrition is an important factor influencing the diversity index. In our study, the nonlinear responses of productivity and diversity of alpine meadow were described by using the multiple levels of degradation in space. The results suggested that aboveground productivity cannot interpret the degree of degradation of alpine meadow, and by contrast, alpine meadow degradation should be measured by the change of plant functional groups, such as edible grasses and poisonous forbs.

Key words alpine meadow; degeneration gradients; species diversity; productivity; nonlinear response

Chen N, Zhang YJ, Zhu JT, Li JX, Liu YJ, Zu JX, Cong N, Huang K, Wang L (2018). Nonlinear responses of productivity and diversity of alpine meadow communities to degradation. Chinese Journal of Plant Ecology, 42, 50-65. DOI: 10.17521/cjpe.2017.0252

高寒草甸是青藏高原广泛分布的主要植被类型, 也是我国草地生态系统的重要组成部分。据粗略测 算, 青藏高原的高寒草甸面积为 $70 \times 10^{4} \mathrm{~km}^{2}$, 约占 青藏高原可利用草场面积的 $50 \%$ 。特殊的地理特征 和恶劣的环境条件, 以及草甸资源存在粗放经营、 不合理利用和管理混乱等问题, 导致草甸退化现象 尤为突出 (王根绪等, 2000; 周华坤等, 2005; 罗亚勇 等, 2012; 刘晓琴等, 2013)。自20世纪80年代以来, 覆盖青藏高原面积 $37 \%$ 的高寒草甸原生植被严重退 化(罗亚勇等, 2014)。以那曲地区为例, 该地区草地 退化面积为 $1.81 \times 10^{7} \mathrm{hm}^{2}$, 占该地区土地总面积的 $43.1 \%$, 其中轻度退化面积占退化草地总面积的 $57.3 \%$, 中度退化面积占 $38.3 \%$, 重度退化面积占 $4.4 \%$ (毛飞等, 2008)。

近些年在全球气候变化和人类活动加剧的背景 下, 青藏高原高寒草甸面临着严峻的退化问题(盛 丽和王彦龙2010)。与全球气候变干、变暖的趋势相 同, 青藏高原气候面临着干暖趋势(杨富裕等, 2003), 由此引发的负面影响更为突出(蔡晓布等, 2007), 例 如气温增幅大、降水量持续降低(邹学勇等, 2003)、 冻土层变薄(钟祥浩, 2005)等。气候变化引起的不利 因素与大风等因素相结合加剧了土壤水蒸发, 尤其 在地表物质疏松、土壤团粒结构和有机质含量低的 条件下, 更易引发土壤风蚀, 加剧土地沙漠化、盐碱 化, 进而严重抑制草地植被的生长(蔡晓布等, 2007), 并且高寒草原植被相对比较稀疏、根系较浅, 导致 这种状况进一步恶化(盛丽和王彦龙, 2010)。但是相 对于气候变化对青藏高原草地退化的影响, 人类活 动的影响更加严重(李明森, 2000)。过度放牧被认为 是导致草地退化最重要的人为因素, 畜牧业是藏北 高原支柱型产业, 近些年发展速度不断加快, 规模
不断扩大，已远远超过天然草地的承载能力(张建 平等, 2001)。过度放牧与草地不合理利用、鼠害等 因素共同导致土壤退化、沙化，而且由于草地土壤 养分大量输出, 土壤容重、肥力、植被的种类和数 目发生明显变化(董孝斌和张新时, 2005; 赵成章等, 2005; 王云霞和曹建民，2007)。研究发现畜种、畜 群的构成中存在严重的不合理性, 饲草在季节间存 在不平衡, 这些因素将进一步加剧过度放牧对草地 生态系统的负面影响(西藏自治区农牧业特色产业 发展研究课题组, 2003), 导致人为因素对草地退化 的影响更大。

草地退化是一个复杂的生态过程, 虽然关于退 化的原因和机理在不同区域和不同草地类型中存在 一定争议(王德利等, 1996; 张国胜和李林, 1999), 但是有关退化引起物种组成及生产力发生变化的结 论是一致的(李里和刘伟, 2011)。草地退化程度越严 重, 其群落结构越简单, 原群落中的优势物种逐渐 在竞争中被适口性较差的一些物种取代, 导致优良 牧草数量减少, 盖度降低, 而杂类草等适口性差的 物种数量逐渐增加, 群落的多样性、丰富度和均匀 度逐渐降低(祁彪等, 2005; 周华坤等, 2005; 宗宁等, 2010; 罗亚勇等, 2014), 但随着退化程度加剧, 物 种多样性不一定总是降低, 也可能增加(仁青吉等, 2008)。即使不考虑物种多样性对退化的正负响应, 也可能存在其他响应模式, 例如研究表明, 中度退 化草地的物种多样性最高(周华坤等, 2005; 郑伟等, 2012), 物种多样性对退化的响应呈现先稳定后降 低的趋势(罗亚勇等, 2014), 因此在物种多样性对退 化的响应过程中可能存在非线性的响应模式。

群落生产力是衡量群落生态功能的最重要指标, 能够反映群落结构及其功能的变化。在高寒草甸退 
化过程中, 土壤质地、养分和水分等复杂变化及其 相互关系共同调控物种多样性和群落生产力的变化 (罗亚勇等, 2014)。随着退化程度的加剧, 禾本科及 莎草科等优良牧草的地上生物量下降, 杂类草生物 量明显升高, 在群落中逐渐占据优势地位, 使草地 总生物量不断减少, 草地生产力降低( 仁青吉等, 2008; 李里和刘伟, 2011; 陈乐乐等, 2016), 但是与 多样性对退化的响应趋势类似, 罗亚勇等(2014)研 究发现, 随着高寒草甸退化程度的加剧, 植被群落 地上生物量呈先稳定后降低的趋势, 地上生物量在 轻度退化阶段或者中度退化阶段最高, 在极度退化 阶段最低(刘伟等, 1999; 周华坤等, 2005)。然而, 在 物种多样性和群落生产力对退化的响应过程中, 多 数研究定量比较不同退化阶段的群落生物量之间的 差异, 可能不能充分揭示生产力对退化的具体响应 模式。

综上所述, 以往的研究多关注不同退化阶段生 产力和多样性的响应程度及其影响因素, 而关于群 落生产力和物种多样性在退化过程中的动态响应, 即线性或者非线性响应研究较少。本研究依托中国 科学院地理科学与资源研究所高原生态系统研究中 心藏北高原草地生态系统研究站(那曲站), 采用熵 权法划分出 5 个退化等级, 即对照、轻度退化、中度 退化、重度退化和极度退化等, 从2016年开始, 获取 两个生长季的连续群落调查和取样数据, 分析在高 寒草甸退化过程中生产力和物种多样性的非线性响 应, 揭示青藏高原高寒草甸退化的关键生态过程及 影响因素。

\section{1 材料和方法}

\section{1 研究区域概况}

研究区域位于藏北高原核心地带, 那曲地区那 曲县那曲镇曲果仁毛村境内的藏北高原草地生态系 统研究站(那曲站) $\left(31.64^{\circ} \mathrm{N}, 92.02^{\circ} \mathrm{E}\right.$, 海拔4 $\left.585 \mathrm{~m}\right)$, 隶属于中国科学院地理科学与资源研究所。那曲县 属于高原亚寒带季风半湿润气候区。全年大风日100 天左右, 平均风速 $2.7 \mathrm{~m} \cdot \mathrm{s}^{-1}$, 最大风速可达 26.3 $\mathrm{m} \cdot \mathrm{s}^{-1}$; 年平均气温 $-1.16{ }^{\circ} \mathrm{C}$, 全年日照时间 $2788 \mathrm{~h}$; 年降水量430 mm, 集中在6-9月, 占全年降水量的 $85 \%$ (数据来源于中国气象科学数据共享服务网那 曲站点)。全年无绝对无霜期, 每年10月至次年5月 为风雪期和土壤冻结期(朱军涛, 2016)。植被类型为
典型的高寒草甸, 优势种为高山嵩草(Kobresia pygmaea), 常见伴生种有钉柱委陵菜(Potentilla saundersiana)、无茎黄鹤菜(Youngia simulatrix)、藏西风 毛菊(Saussurea stoliczkai)、矮羊茅(Festuca coelestis)、楔叶委陵菜(Potentilla cuneata)、矮火线草 (Leontopodium nanum) 等。土壤类型为高寒草甸土 (朱军涛, 2016)。

\section{2 实验设计}

根据研究区高寒草甸的退化程度, 采用草地退 化五级梯度标准, 即对照、轻度退化、中度退化、 重度退化和极度退化。在 5 个退化梯度上各选取坡度 $<10^{\circ}$ 较为平缓的 6 个(即 6 个重复) $6 \mathrm{~m} \times 6 \mathrm{~m}$ 的典型样 地(图1), 共计30块实验样地。在每个样地中选取一 个 $4 \mathrm{~m} \times 4 \mathrm{~m}$ 的核心样地, 将核心样地分割成 4 个 $2 \mathrm{~m} \times 2 \mathrm{~m}$ 的子区域(A, B, C, D), 在A区域内随机选 取 1 个 $1 \mathrm{~m} \times 1 \mathrm{~m}$ 的永久样方, 用于调查植物的高度、 盖度和多度; B区域用于测定地上和地下生物量; C区 域用于测定碳通量; D区域用于未来的相关研究 (图1)。

\section{3 野外调查和取样}

在2016年和 2017 年生长季, 对永久样方进行植 物群落调查; 然后在B区域随机选取 $0.5 \mathrm{~m} \times 0.5 \mathrm{~m}$ 的样方分种剪草, 带至室内在烘箱烘干至恒质量后 称量 $\left(65{ }^{\circ} \mathrm{C}\right.$; 大约 $\left.48 \mathrm{~h}\right)$; 同时, 在剪去植物地上部分 后, 使用直径为 $7.0 \mathrm{~cm}$ 的土钻采集 $0-10 \mathrm{~cm} 、 10-20 \mathrm{~cm}$ 和20-30 cm 的土壤样品, 为了避免土壤样品的分析 误差, 所有土壤样品的采集均在晴朗的上午集中进

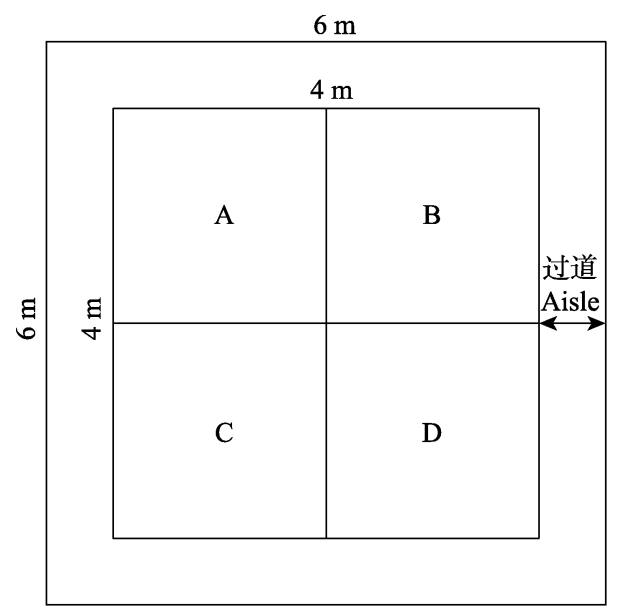

图1 样地布设图。A, 群落调查; B, 测定生物量; C, 测定碳 通量; D, 未来的相关研究。

Fig. 1 Plot layout. A, community survey; B, measure biomass; $\mathrm{C}$, measure carbon flux; $\mathrm{D}$, future related researches. 
行; 并将收集到的土壤样品使用 $1 \mathrm{~mm}$ 的土壤篎将 根系从土壤中分离, 过篮后的根系样品及时洗净后 烘干至恒质量 $\left(65^{\circ} \mathrm{C}\right.$; 大约 $\left.48 \mathrm{~h}\right)$ 后称质量。

\section{4 相关指标的测定}

\subsection{1 全碳 $(\mathrm{C})$ 、全氮 $(\mathrm{N})$ 分析}

将采集到的 3 层土壤样品过 $1 \mathrm{~mm}$ 的网篮，自然 风干、磨碎并过 60 目 $(0.27 \mathrm{~mm})$ 网笁。土壤全C、全 $\mathrm{N}$ 利用干烧法进行测量, 在纯氧环境下, 样品在相 应试剂中燃烧或在惰性气体中高温裂解, 转化为 $\mathrm{CO}_{2} 、 \mathrm{~N}_{2}$, 然后通过色谱柱分离后, 分别进行热导检 测, 得到 $\mathrm{C} 、 \mathrm{~N}$ 的质量分数, 上述分析是在元素分析 仪(Elementar Analysensysteme GmbH, Hesse, Germany)中进行, 本文测量的全 $\mathrm{C} 、$ 全 $\mathrm{N}$ 是表层 $0-10 \mathrm{~cm}$ 土 壤的 $\mathrm{C} 、 \mathrm{~N}$ 含量。

\subsection{2 土壤体积含水量}

土壤体积含水量利用 TDR300土壤水分仪 (Spertrum, New York, USA)测定, 分别测定 $7.6 \mathrm{~cm}$ 、 $12 \mathrm{~cm}$ 深处土壤含水量, 每10天测定一次。

\subsection{3 土壤物理特征指标}

使用容重测定后的土壤样品进行土壤砾石含量 (土石比)的测定。基于 0-5、5-10、10-20、20-30、 30-50、50-70、70-100 cm不同土壤深度对每层容重 样品烘干称质量后, 计环刀内土壤样品干质量为 $m 1$, 体积为 $V 1$ 。将环刀内土壤取出后放入塑料盆中, 注 入清水, 用手搅拌土体, 使得砾石和土壤分离, 待 砾石沉底后, 倒掉泥水。如此反复几次, 使土壤和砾 石彻底分离, 用吸水纸吸干砾石表面水分。将砾石 放入到孔径为 $2 \mathrm{~mm}$ 的网篮内过篮。反复摇晃后, 篮 内的砾石即为粒径 $>2 \mathrm{~mm}$ 的砾石, 并称量其质量 $m 2$ 。选择适当大小的量筒, 注入一定体积的水, 记 下水的刻度 $H 1$ 。将粒径 $>2 \mathrm{~mm}$ 的砾石放入量筒内, 记下水的刻度 $H 2$ 。粒径 $>2 \mathrm{~mm}$ 的砾石体积为 $V 2=$ $H 2-H 1$ 。在试验中, 需要选择适当的量筒, 如果量筒 过大, 精确度不够, 量筒过小, 则水容易溢出。砾石 含量体积比和质量比计算公式如下:

砾石含量 $($ 体积比 $)=\frac{V 2}{V 1} \times 100 \%$
砾石含量 $($ 质量比 $)=\frac{m 2}{m 1} \times 100 \%$

\section{5 物种多样性的计算}

通过选用物种丰富度指数 $(C)$ 、辛普森指数 $(D)$ 、 香农多样性指数 $(H)$ 和均匀度指数 $(J)$ 4类多样性指
数来计算群落的物种多样性(左小安等, 2007), 上述 4种指数的计算均使用孔凡洲等(2012)的计算方法。

物种丰富度指数 $(C)$ :

$$
C=\frac{(S-1)}{\ln N}
$$

辛普森指数 $(D)$ :

$$
D=1-\sum_{i=1}^{S} P^{2}{ }_{i}
$$

其中, $P_{i}^{2}=\frac{n_{i}\left(n_{i}-1\right)}{N_{i}\left(N_{i}-1\right)}$

香农多样性指数 $(H)$ :

$H=-\sum_{i=1}^{S} P_{i} \ln P_{i}$

均匀度指数 $(J)$ :

$J=H / \ln S$

式中: $S$ 为群落中物种数; $N$ 为所有物种的个体数之 和; $n_{\mathrm{i}}$ 为第 $i$ 个种的个体数。

\section{6 数据分析}

采用单因素方差分析检验不同退化程度间的物 种盖度、生物量、多样性指数等指标的差异; 使用 Pearson相关分析判定多样性指数的影响因素, 以上 分析在SPSS 20.0 (SPSS, Chicago, USA)中实现。在R 3.3.0中分别使用线性函数和非线性函数拟合物种盖 度、生物量、多样性指数对高寒草甸退化的线性和 非线性响应。本文在选取有关退化指标的基础上, 在Excel中使用摘权法评价不同退化梯度的综合 得分。

在Amos 21.0中使用结构等式模型(SEM)分析 生物量的直接和间接影响因素, 具体步骤如下:

\subsection{1 结构方程和测量方程设立}

结构等式模型假定一组隐变量之间存在相关关 系, 隐变量是几个显变量的线性组合(侯杰泰和成 子娟, 1999)。通过检验显变量之间的相关系数或协 方差, 进而估计模型中的通径系数, 因此可以在统 计上检验所假设的模型对所研究的过程是否合适。

结构等式模型的表达式如下:

$$
\begin{aligned}
& \eta=\beta \eta+\alpha \xi+\varsigma \\
& x=\Lambda_{X} \xi+\delta \\
& y=\Lambda_{Y} \eta+\varepsilon
\end{aligned}
$$

公式(1)是结构等式模型中的结构模型, 阐述隐 变量与显变量之间的关系。其中, $\eta$ 是隐变量向量, $\beta$ 是隐变量 $\eta$ 的系数矩阵, 同时也是隐变量间通径 
系数矩阵; $\xi$ 是显变量向量; $\alpha$ 是显变量 $\xi$ 的系数 矩阵, 同时也是显变量对应内生潜变量的通径系数 矩阵; $\varsigma$ 是残差向量。

公式(2)和(3)是结构等式模型中的测量模型。测 量模型通常由两个方程构成, 分别表示显变量向量 $\xi$ 和观测变量 $x$ 之间, 及隐变量向量 $\eta$ 和内生的观 测变量 $y$ 之间的联系。 $\Lambda_{X}$ 为观测变量 $x$ 在显变量 向量 $\xi$ 上的因子载荷矩阵, $\delta$ 是公式(2)的误差向量; $\Lambda_{Y}$ 为观测变量 $y$ 在隐变量向量 $\eta$ 上的因子载荷矩 阵, $\varepsilon$ 是公式(3)的误差向量。

\subsection{2 变量的选取}

由于过度放牧使家畜对草地土壤的践踏作用加 剧, 造成土壤紧实度增加, 容重上升, 砂粒含量逐 渐增加, 因此导致土壤持水力降低, 土壤水分含量 减少(赵成章等, 2005; 王云霞和曹建民, 2007); 在 此过程中土壤 $\mathrm{pH}$ 值升高, 土壤养分逐渐降低(罗亚 勇等, 2014), 而土壤理化性质的改变将直接影响植 被的生长、发育及演替过程(贺金生等, 2003), 并且 土壤理化性质的改变及其相互关系共同决定着高寒 草甸生产力的变化。基于以上理论支持, 本文利用 结构等式模型(SEM)解析土壤 C含量, 碎石质量比, 体积含水量的改变对群落中高山嵩草盖度、矮火线 草盖度和总盖度及地上、地下生物量的直接和间接 影响。

\subsubsection{SEM整体模型适配度评价}

本文选取 $\chi^{2}$ 、绝对适配度指数 $(R M S E A,<0.05)$ 、 增值适配度指数 $(N F I,>0.9)$ 和最小信息准则 $(A I C)$ (理 论模型的 $A I C$ 值要小于独立模型和饱和模型的 $A I C$ 值)衡量SEM的拟合优度(吴明隆, 2010)。

\section{2 结果分析}

\section{1 不同退化阶段高寒草甸群落盖度}

随着草地退化程度加剧, 群落盖度呈现下降趋 势, 但是线性与非线性的拟合结果没有显著差异 ( $R^{2}$ 值一致)。其中与对照相比, 轻度退化、中度退化、 重度退化与极度退化的群落盖度分别显著降低 $11.5 \%(p<0.01) 、 26.4 \%(p<0.01) 、 64.3 \%(p<0.01)$ 和 $50.7 \%(p<0.01$, 图 $2 \mathrm{~A})$ 。从功能群角度看, 高山 嵩草盖度变化显著, 与对照相比, 轻度退化、中度退 化、重度退化和极度退化处理下的高山嵩草盖度分 别显著降低 $24.6 \%(p<0.01) 、 52.8 \%(p<0.01)$ 、 $89.7 \%(p<0.01)$ 和 $97.7 \%(p<0.01)$, 说明在高寒草
甸退化过程中高山嵩草的响应较敏感(图2B)。与高 山嵩草变化趋势相反, 随着退化程度加剧, 矮火线 草盖度呈现非线性 $\left(R^{2}{ }_{\text {nonlinear }}>R_{\text {linear }}^{2}\right)$ 上升趋势, 其 中在中度退化和极度退化中, 矮火线草盖度分别显 著增加 $371.5 \%(p=0.05)$ 和 $656.0 \%(p<0.01$, 图2D), 而且矮火线草盖度占总盖度的比重在极度退化处理 中超过高山嵩草。委陵菜属的盖度并未随着退化程 度的加剧而显著改变 $(p>0.1$, 图2C)。

\section{2 不同退化阶段高寒草甸群落生产力}

随着退化程度加剧, 地上生物量呈现上升趋势, 与对照相比, 重度退化处理下地上生物量显著提高 $32.3 \%$ (图3A, $p<0.1$ ), 而其他退化处理地上生物量 与对照相比差异不显著(图3A, $p>0.1$ ), 其中线性和 非线性模型拟合趋势并没有明显差异。进一步分析 不同功能群的变化, 我们发现高山嵩草地上生物量 随着退化程度不断加剧, 呈现非线性或线性降低, 其过程大致可以分为两个层次, 第一个层次(对照 到轻度退化), 高山嵩草地上生物量较高, 与对照相 比, 在轻度退化处理下没有显著改变高山嵩草地上 生物量(图3 A, $p>0.1$ ); 但是在第二个层次(中度退 化到极度退化), 高山嵩草地上生物量急剧下降, 其 中中度退化和重度退化处理与对照相比, 高山嵩草 地上生物量分别显著降低 $44.7 \%(p<0.01)$ 和 $85.5 \%$ $(p<0.01)$, 其中在极度退化处理中, 高山嵩草地上 生物量为 0 (图3B)。与高山嵩草地上生物量的变化 相反, 矮火线草地上生物量随着退化程度加剧呈现 非线性上升趋势 $\left(R_{\text {nonlinear }}^{2}>R_{\text {linear }}^{2}\right.$, 同样可以分成 两个层次, 第一个层次 (对照到轻度退化) 矮火线草 地上生物量较低, 对照处理下的矮火线草地上生物 量为 0 , 与对照处理相比, 轻度退化处理下的矮火线 草地上生物量没有显著变化(图3D, $p>0.1$ ), 但是在 第二个层次上矮火线草地上生物量迅速增加, 其中 在重度退化处理中达到最大值 $62.5 \mathrm{~g} \cdot \mathrm{m}^{-2}$, 占总生 物量的 $62.5 \%$ (图3 D, $p<0.01$ ), 意味着从重度退化 开始, 矮火线草对地上生物量的贡献超过高山嵩 草。与高山嵩草和矮火线草地上生物量的变化相比, 委陵菜属的地上生物量并没有显著改变(图3C, $p>$ 0.1 )。

与地上生物量相比, 在高寒草甸退化过程中, 地下生物量的响应较地上生物量更加强烈, 呈现出 显著的非线性下降趋势 $\left(R_{\text {nonlinear }}^{2}>R_{\text {linear }}^{2}\right.$ 。其中与 对照实验处理相比, 轻度退化、中度退化、重度退 

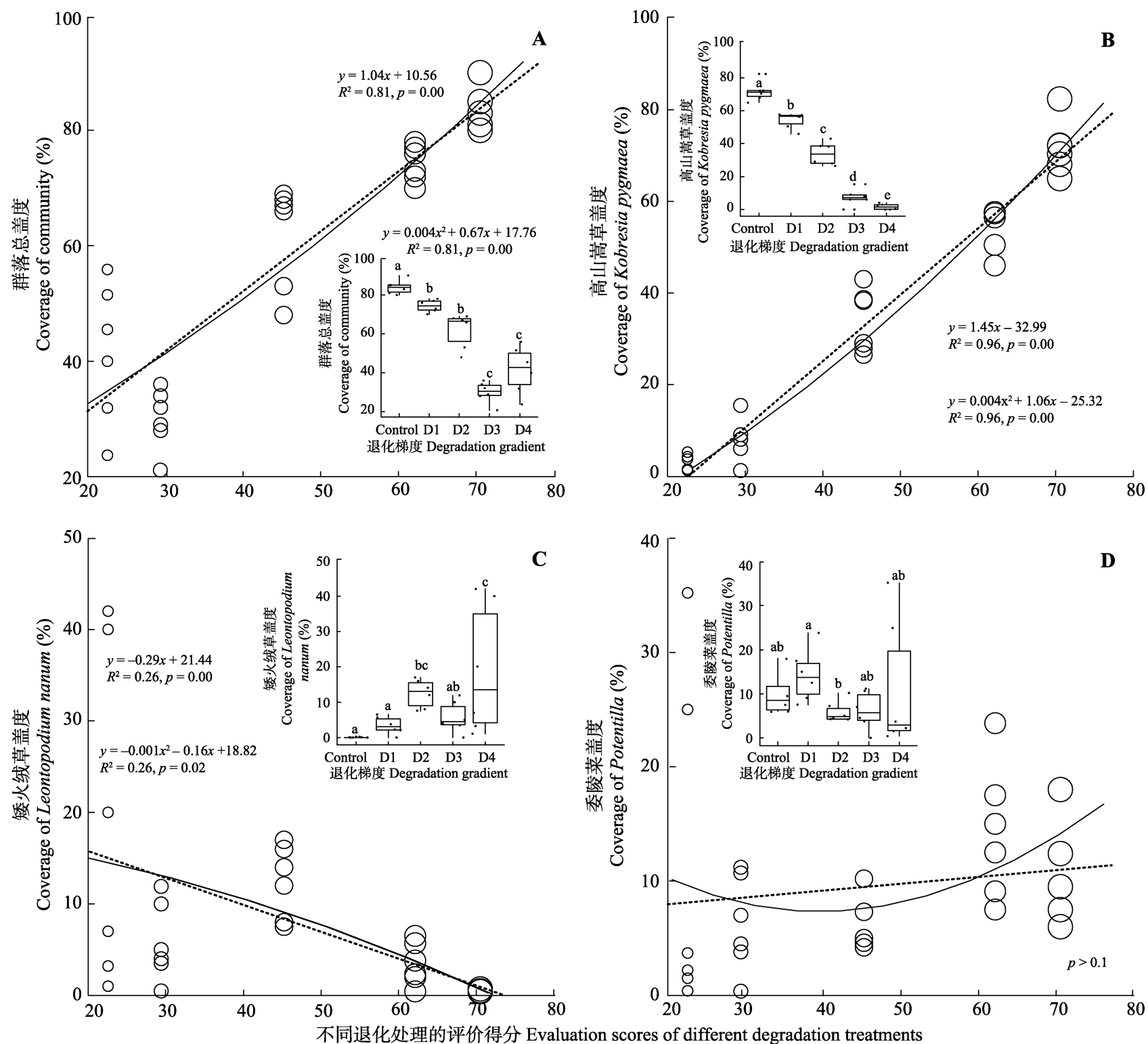

$\bigcirc$ control $\bigcirc \mathrm{D} 1 \bigcirc \mathrm{D} 2 \bigcirc \mathrm{D} 3 \bigcirc \mathrm{D} 4$

图2 不同退化阶段高寒草甸的群落盖度。图中不同字母表示处理之间有显著差异 $(p<0.1)$ 。实线是非线性拟合结果，虚线是 线性拟合结果。Control, 对照, 无退化草甸; D1, 轻度退化草甸; D2, 中度退化草甸; D3, 重度退化草甸; D4, 极度退化草甸。

Fig. 2 The community coverage of alpine meadow in different degradation stages. Different letters in figures indicate significant difference $(p<0.1)$. The solid lines are nonlinear fitting results. Dotted lines are linear fitting results. Control, non-degraded meadow; D1, mild degraded meadow; D2, moderate degraded meadow; D3, severe degraded meadow; D4, serious sandy meadow.

化和极度退化处理下的地下生物量显著降低, 分别 降低24.4\% $(p<0.01), 68.1 \%(p<0.01), 87.8 \%(p<$ $0.01)$ 和 $94.4 \%(p<0.01$, 图 4$)$ 。与地下生物量变化趋 势一致，在高寒草甸退化过程中，总生物量呈现出 显著的非线性下降趋势。其中与对照处理相比, 轻 度退化处理降低总生物量的 $24.2 \%(p<0.01)$, 中度 退化降低67.1\% $(p<0.01)$, 重度退化降低 $86.4 \%$ $(p<0.01)$, 极度退化降低93.1\% (图4, $p<0.01$ )。

\section{3 不同退化阶段高寒草甸物种多样性特征}

随着退化程度不断加深, 辛普森指数、丰富度
指数、香农多样性指数和均匀度指数均呈现出显著 的非线性上升趋势 $\left(R_{\text {nonlinear }}^{2}>R_{\text {linear }}^{2}\right.$, 并且物种多 样性测度结果表明, 轻度、中度、重度和极度退化 草甸的物种辛普森指数 $(p<0.05)$ 、丰富度指数 $(p<$ $0.05)$ 、香农多样性指数 $(p<0.01)$ 和均匀度指数 $(p<$ 0.05)均显著高于对照处理(图5)。四个不同退化阶段 的高寒草甸物种多样性指数的变化趋势大致可以分 为两个层次: 第一个层次具有较低的物种丰富度、 均匀度和多样性, 这一层次主要是以高山嵩草为优 势物种的轻度和中度退化草甸群落; 第二个层次具 

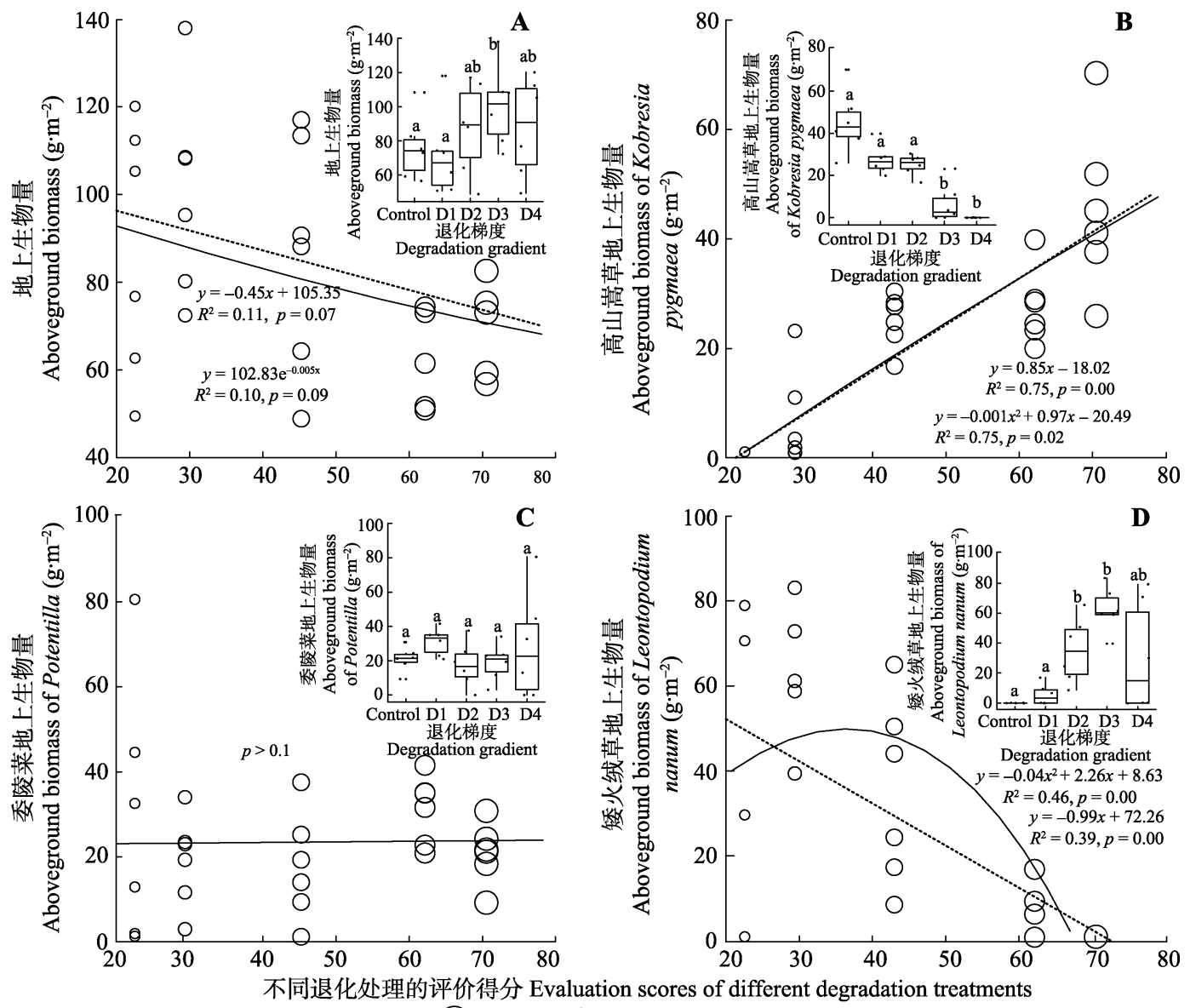

$\bigcirc$ control $\bigcirc \mathrm{D} 1 \bigcirc \mathrm{D} 2 \bigcirc \mathrm{D} 3 \bigcirc \mathrm{D} 4$

图3 不同退化阶段高寒草甸的地上生物量。图中不同字母表示处理之间有显著差异 $(p<0.1)$ 。实线是非线性拟合结果，虚线 是线性拟合结果。Control, 对照, 无退化草甸; D1, 轻度退化草甸; D2, 中度退化草甸; D3, 重度退化草甸; D4, 极度退化草甸。

Fig. 3 The aboveground biomass of alpine meadow in different degradation stages. Different letters in figures indicate significant difference $(p<0.1)$. The solid lines are nonlinear fitting results. Dotted lines are linear fitting results. Control, non-degraded meadow; D1, mild degraded meadow; D2, moderate degraded meadow; D3, severe degraded meadow; D4, serious sandy meadow.
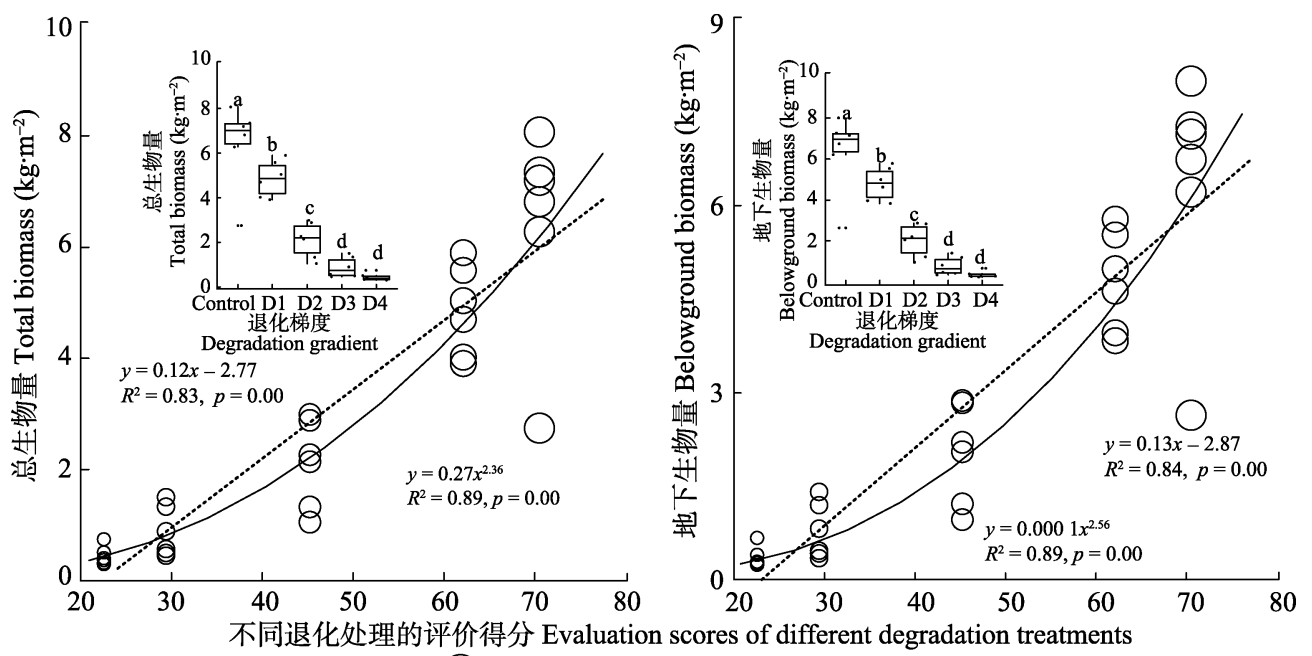

Control $\bigcirc \mathrm{D} 1 \bigcirc \mathrm{D} 2 \bigcirc \mathrm{D} 3 \circ \mathrm{D} 4$

图4 不同退化阶段高寒草甸的总生物与地下生物量。图中不同字母表示处理之间有显著差异 $(p<0.1)$ 。实线是非线性拟合结 果, 虚线是线性拟合结果。Control, 对照, 无退化草甸; D1, 轻度退化草甸; D2, 中度退化草甸; D3, 重度退化草甸; D4, 极度 退化草甸。

Fig. 4 The total biomass and belowground biomass of alpine meadow in different degradation stages. Different letters in figures indicate significant difference $(p<0.1)$. The solid lines are nonlinear fitting results. Dotted lines are linear fitting results. Control, non-degraded meadow; D1, mild degraded meadow; D2, moderate degraded meadow; D3, severe degraded meadow; D4, serious sandy meadow.

www.plant-ecology.com 

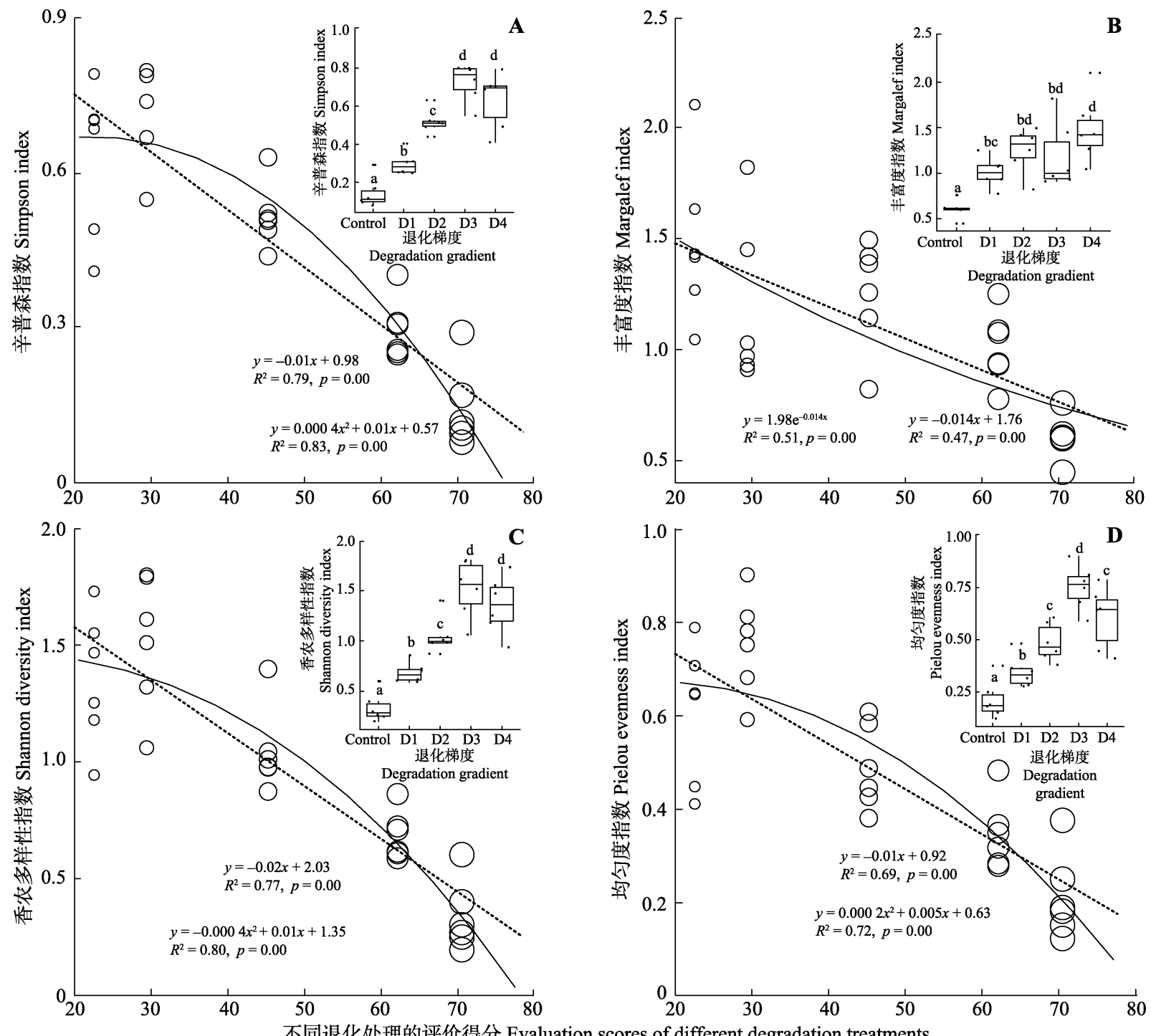

$\bigcirc$ Control $\bigcirc \mathrm{D} 1 \bigcirc \mathrm{D} 2 \bigcirc \mathrm{D} 3 \circ \mathrm{D} 4$

图5 不同退化阶段高寒草甸的生物多样性。图中不同字母表示处理之间有显著差异 $(p<0.1)$ 。实线是非线性拟合结果，虚线 是线性拟合结果。Control, 对照, 无退化草甸; D1, 轻度退化草甸; D2, 中度退化草甸; D3, 重度退化草甸; D4, 极度退化草甸。 Fig. 5 The species diversity of alpine meadow in different degradation stages. Different letters in figures indicate significant difference $(p<0.1)$. The solid lines are nonlinear fitting results. Dotted lines are linear fitting results. Control, non-degraded meadow; D1, mild degraded meadow; D2, moderate degraded meadow; D3, severe degraded meadow; D4, serious sandy meadow.

有较高的物种丰富度、均匀度和多样性, 是逐渐以 矮火线草为优势种的重度和极度退化群落(图5)。

\section{4 不同退化阶段高寒草甸土壤理化性质变化特征}

随着退化程度不断加剧, 土壤 $\mathrm{C} 、 \mathrm{~N}$ 含量呈现出

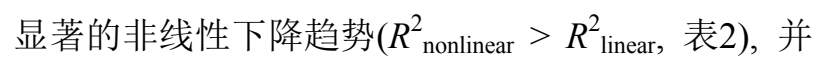
且变化趋势较为一致, 从轻度退化到极度退化可以 清晰地划分为两个阶段, 第一阶段(对照到中度退 化)中不同退化程度的高寒草甸土壤 $\mathrm{N}$ 和 $\mathrm{C}$ 含量并没 有发生显著改变(表 $1, p>0.1$ ); 第二阶段中重度退 化和极度退化与对照, 轻度退化和中度退化相比均 显著降低土壤中的 $\mathrm{N}$ 和 $\mathrm{C}$ 含量, 与对照处理相比, $\mathrm{N}$
含量分别降低 $28.5 \%(p<0.05)$ 和 $23.6 \%(p<0.1), \mathrm{C}$ 含量分别降低 $39.2 \%(p<0.01)$ 和 $32.5 \%(p<0.01)$ (表1)。

我们的研究发现, 随着退化程度加剧, 土壤容 重、砾石质量比、砾石体积比呈现出显著的非线性 上升趋势 $\left(R_{\text {nonlinear }}^{2}>R_{\text {linear }}^{2}\right.$, 其中只有非线性模型 才能拟合砾石质量比对高寒草甸退化的响应(表2)。 土壤的物理特征表明，土壤容重、砾石质量比和砾 石体积比整体呈现上升趋势, 并且变化趋势较为一 致, 从轻度退化到极度退化可以大致划分为两个阶 段, 其中土壤容重在第一阶段(对照到轻度退化), 
表1 不同退化阶段高寒草甸的土壤理化特征

Table 1 The soil physicochemical properties of alpine meadow in different degradation stages

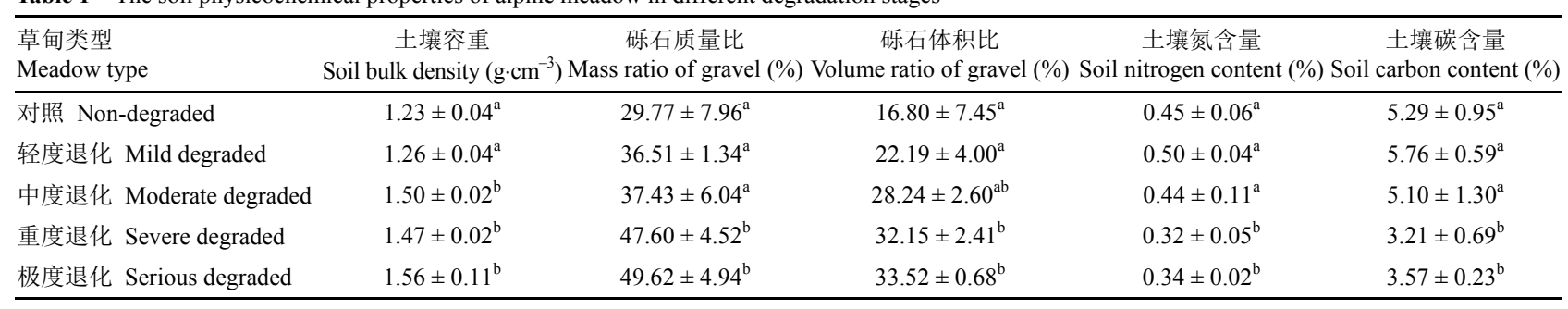

不同字母表示处理之间有显著差异 $(p<0.1)$ 。

Different letters indicate significant difference $(p<0.1)$.

表2 高寒草甸退化过程中土壤理化性质线性和非线性响应比较

Table 2 Comparison between linear and nonlinear responses of soil physicochemical properties to alpine meadow degradation

\begin{tabular}{|c|c|c|}
\hline & $R^{2}$ & 拟合模型 Fitted model \\
\hline \multicolumn{3}{|l|}{ 土壤容重 Soil bulk density } \\
\hline 线性模型 Linear model & $0.66^{* * *}$ & $y=-0.006 x+1.695$ \\
\hline 非线性模型 Nonlinear model & $0.76^{* * *}$ & $\begin{array}{l}y=0.0002 x^{2}+0.012 x+ \\
1.326\end{array}$ \\
\hline \multicolumn{3}{|l|}{ 砾石质量比 Mass ratio of gravel } \\
\hline 线性模型 Linear model & 0.13 & $y=-0.155 x+47.310$ \\
\hline 非线性模型 Nonlinear model & $0.53^{*}$ & $\begin{array}{l}y=0.023 x^{2}-2.326 x+ \\
89.838\end{array}$ \\
\hline \multicolumn{3}{|l|}{ 砾石体积比 Volume ratio of gravel } \\
\hline 线性模型 Linear model & $0.44^{* *}$ & $y=0.240 x+37.607$ \\
\hline 非线性模型 Nonlinear model & $0.58^{* *}$ & $\begin{array}{l}y=0.011 x^{2}-1.300 x+ \\
58.371\end{array}$ \\
\hline \multicolumn{3}{|l|}{ 土壤氮含量 Soil nitrogen content } \\
\hline 线性模型 Linear model & $0.42^{* * *}$ & $y=0.003 x+0.264$ \\
\hline 非线性模型 Nonlinear model & $0.46^{* * *}$ & $\begin{array}{l}y=-0.0001 x^{2}+0.011 x+ \\
0.115\end{array}$ \\
\hline \multicolumn{3}{|l|}{ 土壤碳含量 Soil carbon content } \\
\hline 线性模型 Linear model & $0.50^{* * *}$ & $y=0.049 x+2.35$ \\
\hline 非线性模型 Nonlinear model & $0.55^{* * *}$ & $\begin{array}{l}y=-0.001 x^{2}+0.159 x+ \\
0.183\end{array}$ \\
\hline
\end{tabular}

*、**、***分别表示在 $10 \% 、 5 \% 、 1 \%$ 的置信水平上具有差异显著性。 $*, * *, * * *$ represent statistically significant at the $10 \%, 5 \%, 1 \%$ confidence level, respectively.

没有随着退化程度的加剧而显著改变。在第二阶段 (中度退化到极度退化), 与对照和轻度退化相比, 中 度退化、重度退化和极度退化均显著增加土壤容重, 其中与对照相比, 分别显著增加土壤容重 $20.6 \%(p<$ $0.05) 、 19.1 \%(p<0.05)$ 和 $26.4 \%(p<0.05)($ 表 1$)$ 。与 土壤容重不同, 土壤砾石质量比和砾石体积比的第 一阶段是从对照到中度退化处理, 其中在第一阶段 土壤砾石质量比和体积比没有显著改变; 但是在第 二阶段 (重度退化到极度退化), 与对照相比, 重度 退化和极度退化土壤砾石质量比分别显著增加 $59.9 \%$ $(p<0.05)$ 和 $66.7 \%(p<0.05)$, 显著增加土壤砾石体 积比 $91.4 \%(p<0.01)$ 和 $99.6 \%(p<0.01)$ (表 1$)$ 。

在高寒草甸退化过程中, 土壤中 $0-7.6 \mathrm{~cm}$ 和 0-12 cm两个层次中土壤含水量并没有呈现出明显 的非线性响应趋势(表3)。不同退化阶段高寒草甸土
壤含水量特征表明, 土壤中 $0-7.6 \mathrm{~cm}$ 和 $0-12 \mathrm{~cm}$ 两个 层次中土壤含水量呈现下降趋势, 变化趋势一致, 从轻度退化到极度退化可以清晰地划分为两个阶段, 在第一阶段(对照到中度退化), 不同退化程度的高 寒草甸土壤中 $0-7.6 \mathrm{~cm}$ 和0-12 $\mathrm{cm}$ 含水量并没有发 生显著改变(图6, $p>0.1)$; 但是与第一阶段相比, 第 二阶段中重度退化和极度退化与对照、轻度退化和 中度退化相比均显著降低土壤中 0-7.6 $\mathrm{cm}$ 和0-
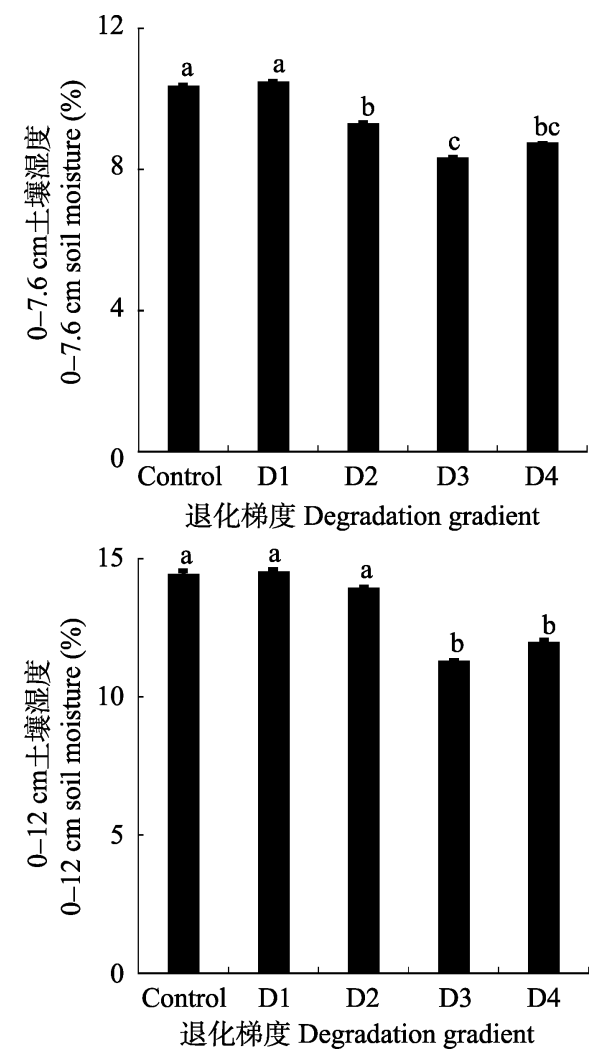

图6 不同退化阶段高寒草甸的土壤含水量特征(平均值土标 准误差)。不同字母表示处理之间有显著差异 $(p<0.1)$ 。 Control, 对照, 无退化草甸; D1, 轻度退化草甸; D2, 中度退 化草甸; D3, 重度退化草甸; D4, 极度退化草甸。

Fig. 6 The soil water content of alpine meadow in different degradation stages (mean $\pm S E$ ). Different letters indicate significant difference $(p<0.1)$. Control, non-degraded meadow; D1, mild degraded meadow; D2, moderate degraded meadow; D3, severe degraded meadow; D4, serious sandy meadow. 
表3 高寒草甸退化过程中土壤含水量的线性和非线性响应比较

Table 3 Comparison between linear and nonlinear responses of soil water content to alpine meadow degradation

\begin{tabular}{|c|c|c|}
\hline & $R^{2}$ & 拟合模型 Fitted model \\
\hline \multicolumn{3}{|l|}{$0-7.6 \mathrm{~cm}$ 土层 $0-7.6 \mathrm{~cm}$ soil layer } \\
\hline 线性模型 Linear model & $0.61^{* * *}$ & $y=0.044 x+7.396$ \\
\hline 非线性模型 Nonlinear model & $0.61^{* * *}$ & $y=7.557 \mathrm{e}^{0.005 \mathrm{x}}$ \\
\hline \multicolumn{3}{|l|}{$0-12 \mathrm{~cm}$ 土层 $0-12 \mathrm{~cm}$ soil layer } \\
\hline 线性模型 Linear model & $0.39^{* * *}$ & $y=0.066 x+10.148$ \\
\hline 非线性模型 Nonlinear model & $0.41^{* * *}$ & $\begin{array}{l}y=-0.001 x^{2}+0.169 x+ \\
8.136\end{array}$ \\
\hline
\end{tabular}

*、**、***分别表示在 $10 \% 、 5 \% 、 1 \%$ 的置信水平上具有差异显著性。 $*, * *, * * *$ represent statistically significant at the $10 \%, 5 \%, 1 \%$ confidence level, respectively.

$12 \mathrm{~cm}$ 含水量, 与对照相比, 土壤中0-7.6 $\mathrm{cm}$ 水分含 量分别显著降低了 $19.6 \%(p<0.01)$ 和 $15.5 \%(p<$ $0.01)$, 土壤中 0-12 cm水分含量分别显著降低了 $21.9 \%(p<0.01)$ 和 $17.0 \%(p<0.05)$ (图6)。

\section{5 物种多样性、群落生产力与环境因子的关系}

相关性分析结果表明, 土壤 $\mathrm{C}$ 和 $\mathrm{N}$ 含量与均匀 度指数、辛普森指数及香农多样性指数存在显著负 相关关系 $(p<0.05)$, 但是与砾石质量比、砾石体积 比及体积含水量无显著相关关系 $(p>0.1$, 图7), 其

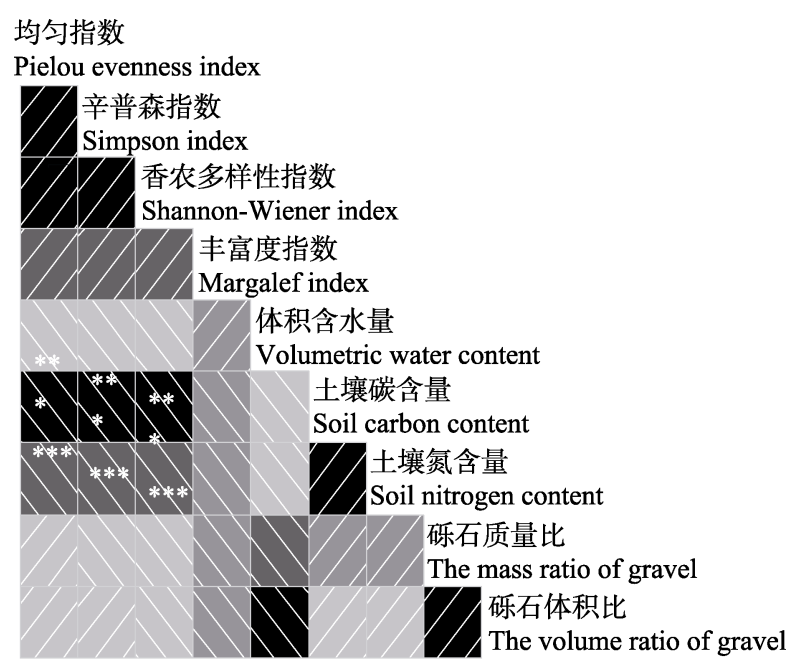

图7 不同退化阶段高寒草甸群落物种多样性与土壤理化性 质之间相关分析。黑色和从左下指向右上的斜杜表示两个变 量正相关, 黑色和从左上指向右下的斜杜表示变量之间负 相关。颜色越深, 饱和度越高, 说明变量相关性越大; * *** $* * *$ 分别表示在 $10 \% 、 5 \% 、 1 \%$ 的置信水平上具有统计显著性。 Fig. 7 Correlation analysis among soil physico-chemical properties and species diversity of alpine meadow community. Black and from lower left to upper right of the slash said two variables are related, and black from the upper left to lower right slash said negative correlation between variables. The deeper the color, the higher the degree of saturation, explanatory variable correlation; *, **,*** represent statistically significant at the $10 \%, 5 \%, 1 \%$ confidence level, respectively.
中物种丰富度指数与土壤 $\mathrm{C} 、 \mathrm{~N}$ 和土壤物理性质均没 有显著相关关系 $(p>0.1)$ 。说明在高寒草甸退过程 中, 物种的多样性主要受到土壤营养成分的影响。

$\mathrm{SEM}$ 结果表明土壤 $\mathrm{C}$ 含量对高山嵩草盖度、 矮火线草盖度和群落总盖度均有显著的直接影 响, 之间的通径系数分别为 $0.71(p<0.01),-0.29$ $(p<0.1)$ 和 $0.16(p<0.05)$, 矮火线草盖度和高山高 草盖度对群落总盖度存在显著的直接影响, 通径系 数为 $0.25(p<0.01)$ 和 $0.88(p<0.01)$, 体积含水量和 群落总盖度对地下生物量有显著的直接影响, 通径 系数为 $0.14(p<0.1)$ 和 $0.99(p<0.01)$ 。碎石质量比和 体积含水量之间的通径系数为 $-0.44(p<0.01))$, 因 此土壤 $\mathrm{C}$ 含量和碎石质量比对地下生物量有间接的 影响, 间接通径系数为0.76 $(p<0.05)$ 和0.07 $(p>$ $0.1)$ 。地下生物量主要受高山嵪草盖度和体积含水 量直接影响, 土壤 $\mathrm{C}$ 含量通过影响高山嵩草盖度间 接影响地下生物量, 但是土壤理化性质对地上生物 量没有显著的直接或间接影响。

\section{3 讨论}

本研究利用空间上的多退化梯度, 探究群落生 产力和物种多样性在退化过程中的动态响应。研究 结果表明, 群落生产力与物种多样性在高寒草甸退 化过程中存在非线性响应模式, 这个重要的变化模 式在以往研究中少有报道(周华坤等, 2005; 左小安 等, 2007; 仁青吉等, 2008; 罗亚勇等, 2014)。

\section{1 高寒草甸退化过程中群落生产力的非线性响应}

我们的研究结果表明, 随着退化程度的不断加 剧, 地上总生物量非线性增加, 该结果与之前的研 究结果(仁青吉等, 2008; 罗亚勇等, 2014)相悖。由于 群落中主要物种对干扰环境变化的响应对策存在差 异，引起群落组成发生变化(Niu et al., 2008), 进而 影响植被过程和生态系统功能。在高寒草甸退化过 程中, 草地生境的改变引起杂类草和毒草的入侵 (Zhang et al., 2005), 导致草地植物功能群发生替代, 优势物种逐渐减少, 杂类草和毒草不断增加, 并且 毒草和杂类草具有较高的地上生物量(罗亚勇等, 2014)。我们的研究结果显示, 矮火线草生物量非线 性增加, 高山嵩草地上生物量非线性降低, 委陵菜 属地上生物量没有显著变化, 在重度退化到极度退 化阶段, 矮火线草地上生物量占地上总生物量的比 重更高, 导致地上生物量非线性增加。但是, 我们的 


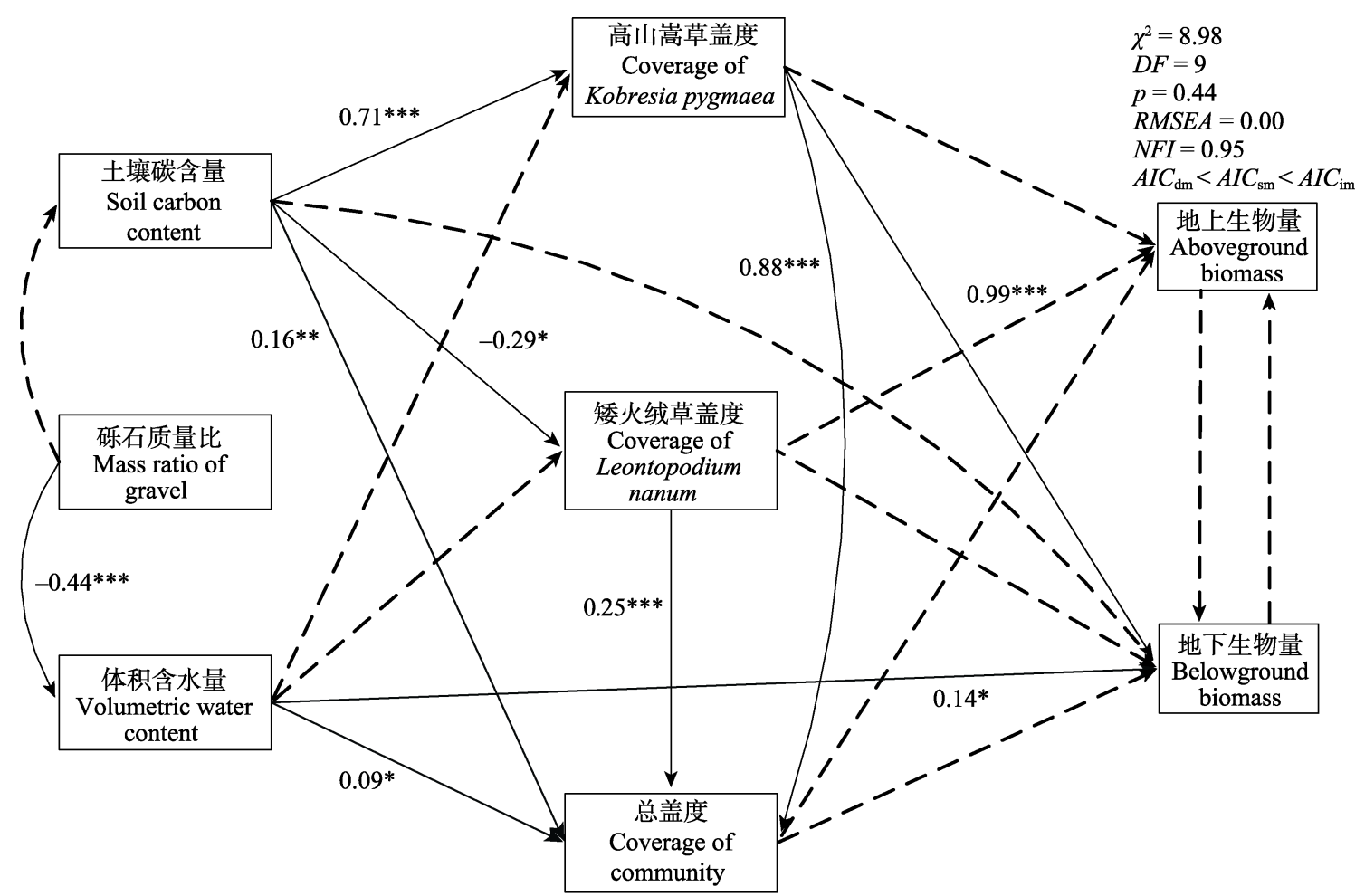

图8 影响地上生物量与地下生物量的直接因素和间接因素的结构等式模型。带有箭头的虚线表示关系不显著 $(p>0.1)$, 实线 表示关系显著 $(p<0.1)$, 带有箭头线上的数字是标准化路径系数 $(*, p<0.1 ; * *, p<0.05 ; * * *, p<0.01)$ 。 AIC, 最小信息准则; $A I C_{\mathrm{dm}}$, 内定模式; $A I C_{\mathrm{im}}$, 独立模式; $A I C_{\mathrm{sm}}$, 饱和模式; $D F$, 自由度; $N F I$, 增值适配度指数; $R M S E A$, 绝对适配指数。

Fig. 8 The results of structural equation models showed the direct and indirect impacts of various factors on biomass and species diversity. A dotted line relationship of the arrow was not significant $(p>0.1)$, the solid line shows the relationship between significantly $(p<0.1)$, the degree of thickness line to reflect the degree of a strong relation between variables, with the arrow line Numbers are standardized path coefficient (*, $\left.p<0.1{ }^{* *}, p<0.05 ; *^{* *}, p<0.01\right)$. AIC, an information criterion; $A I C_{\mathrm{dm}}$, default mode; $A I C_{\mathrm{im}}$, independence model; $A I C_{\mathrm{sm}}$, saturated model; $D F$, degree of freedom; NFI, normed fit index; RMSEA, root mean square error of approximation.

结果未发现土壤理化性质对地上生物量有直接或者 间接的影响, 一方面可能是由于高寒草甸在退化过 程中改变群落中物种组成, 杂类草和毒草比重不断 增加, 而杂类草和毒草资源比率的大小和空间异质 性的高低, 严重制约着物种之间竞争的激烈程度, 从而影响群落生产力的变化(左小安等, 2007); 另一 方面, 可能不同物种对土壤养分和土壤水分的响应 不同, 导致物种间的此消彼长, 最终导致地上生物 量对土壤理化性质变化不敏感。

与地上生物量对退化的响应不同, 随着退化程 度的不断加剧, 地下生物量非线性降低, 与之前研 究(周华坤等, 2005; 罗亚勇等, 2014)结论一致。在水 分胁迫的情况下, 植物的叶片含水量降低得越多, 表明该物种受干旱胁迫就越强, 抗旱能力越弱(谷 燕蓉等, 2005), 研究发现在受到干旱胁迫时, 高山 嵩草的叶片相对含水量较低导致其抗旱能力较弱, 因此在高寒草甸退化过程中, 土壤含水量不断降低,
致使高山嵩草盖度逐渐降低。与此同时, 在退化过 程中土壤 $\mathrm{pH}$ 值不断增加, 土壤养分含量明显降低 (罗亚勇等, 2014), 因此随着高寒草甸退化的不断加 剧, 土壤 $\mathrm{C}$ 含量的显著降低同样会导致高山嵩草盖 度不断下降。研究发现高寒草甸优势物种高山嵩草 属于密从须根型多年生植物, 可以形成庞大的地下 生物量(柳小妮等, 2008), 其根冠比接近70 (龙毅等, 2015), 地下生物量约为委陵菜地下生物量的 60 倍 (龙毅等, 2015), 因此高山嵩草对高寒草甸退化的响 应模式在一定程度上决定地下生物量的变化趋势。 随着退化程度不断加剧, 群落中高山嵩草的比例逐 渐下降, 地下草毡层遭到破坏, 地下生物量迅速降 低, 即使矮火线草的盖度不断增加, 但其属于轴根 型植物, 其数量的增加对地下生物量的贡献较低 (王炜等, 1996), 并且在此过程中伴随着土壤砾石含 量增加、土壤持水力降低, 导致土壤含水量降低, 进 一步加剧地下生物量的降低, 最终这些直接和间接 
因素导致在退化过程中地下生物量的非线性降低。由 于高寒草甸总生物量中, 地下生物量占据主导地位, 因此总生物量的变化主要受地下生物量变异的影响。

\section{2 高寒草甸退化过程中物种多样性的非线性响应}

物种多样性不仅能够度量群落的组成结构和功 能的复杂性, 而且也能指示环境状况, 例如土壤养 分等(罗亚勇等, 2014)。研究结果表明, 在高寒草甸 退化过程中群落多样性呈现出非线性增加趋势, 该 结果与仁青吉等(2008)的研究结果一致。研究进一 步发现, 均匀度指数和多样性指数在重度退化梯度 上达到最大, 物种丰富度指数在极度退化梯度上达 到最大, 与之前的研究结果(柳小妮等, 2008)相似。 造成这种差异的主要原因是群落种类数目和种类之 间个体分配的均匀性，过度放牧抑制了优势物种的 竞争能力, 导致处于竞争弱势物种的入侵和定居成 为可能, 在重度、极度退化阶段物种数增幅较大, 因 此物种丰富度显著增加。同时在重度和极度退化阶 段, 优势种对其他物种的抑制作用明显减弱, 表现 为优势种高山嵩草盖度逐渐降低, 矮火线草盖度逐 渐增加, 因此在重度退化梯度上, 高山嵩草、委陵菜 属和矮火线草在群落中达到相对平衡, 导致均匀度 在重度退化阶段最高。

随着退化程度的加剧, 群落多样性指数非线性 增加, 群落总盖度及高山嵩草盖度非线性降低, 矮 火线草盖度非线性增加, 委陵菜属则没有显著变 化。植物群落的结构特征通常以优势种和其他主要 物种组成为特征, 优势种的更替可成为植物群落演 替的重要表现形式 (Sala et al., 1986; 王炜等, 1996), 在退化过程中, 高寒草甸植被群落逆向演替表现为 原优势种高山嵩草在群落竞争中逐步丧失优势地位, 成为群落的伴生种, 群落向杂类草草地过渡, 最终 形成毒杂草占优势的极度退化草地植被类型。这主 要是因为: 1)过度放牧对高寒草甸退化的影响是一 个综合因素, 其中包括动物的采食和践踏(林慧龙 等, 2008), 以及由此引起的土壤理化状况的改变(高 英志等, 2004; 王启兰等, 2008), 受到干扰后的土壤 表面和原有植物的适度破坏为先锋种提供了小生境, 从而使得新的植物侵入群落, 提高了植物的丰富度 (王长庭等, 2008); 2)高寒草甸植物的竞争主要是光 竞争和营养竞争, 其中竞争力变化较大的是物种对 光资源的获取能力(仁青吉等, 2008), 由于放牧(尤 其是过度放牧)使得高山嵩草被优先采食, 导致高
山嵩草的盖度降低, 进而降低整个群落的光照闭合 度, 使光资源不再是影响物种生长和生存的限制因 子, 光资源的释放使弱势物种在对光资源的竞争过 程中受益，被排斥的物种又重新占据原来的生态位， 使得物种丰富度和多度增加, 主要表现为杂类草的 增加(仁青吉等, 2008), 例如, 本研究中, 随着退化 程度不断加剧, 高山嵩草盖度不断降低, 矮火线草 盖度不断增加, 到极度退化, 矮火线草取代高山嵩 草占领其生态位；3)由于放牧强度的增大导致高寒 草场储存在土壤库中的氮磷元素不断输出, 降低土 壤肥力和生产能力, 进而加速了植物群落的演替 (柳小妮等, 2008)。我们的研究结果表明, 相对于土 壤物理性质, 土壤营养状况是影响高寒草甸退化过 程中物种多样性的重要因素, 该结论与罗亚勇等 (2014)和白永飞等(2000)的研究结果较一致。由于高 寒草甸退化导致土壤 $\mathrm{C} 、 \mathrm{~N}$ 含量非线性降低, 而我们 的结果发现土壤营养状况是影响群落多样性的重要 因素, 因此高寒草甸退化过程中土壤养分的非线性 响应可能导致群落多样性的非线性响应。

\section{4 结论}

青藏高原的主要草地类型一高寒草甸, 近年 来发生了不同程度的退化, 严重威胁高原的畜牧业 可持续发展和生态环境。本研究利用空间上的多退 化梯度, 采用商权法为草地退化等级进行评分, 研 究群落生产力和多样性在退化过程中的动态响应。 我们发现随着高寒草甸退化程度加剧, 地上生物 量和群落多样性指数非线性增加, 而地下生物量 和总生物量非线性降低。进一步分析我们发现, 草 甸退化过程中植物功能群组成发生变化, 例如莎 草科植物减少, 矮火线草等杂类草类增加, 改变了 地上和地下生物量的组成, 进而导致地上和地下 生物量的不同响应。群落多样性变化的原因比较复 杂, 一方面可能是放牧动物的采食和践踏, 引起群 落光资源的释放; 另一方面可能是土壤退化过程 中, 一些耐痊薄和耐干旱的物种入侵, 从而提高了 群落多样性。本研究刻画了高寒草甸群落生产力和 物种多样性的非线性响应模式, 揭示了青藏高原 高寒草甸退化的关键生态过程及影响因素。

致谢 中国科学院生态系统网络观测与模拟重点实 验室青年创新团队项目(LENOM2016Q0002)支持本

DOI: $10.17521 /$ cjpe. 2017.0252 
研究，特此致谢。

\section{参考文献}

Bai YF, Li LH, Wang QB, Zhang LX, Zhang Y, Chen ZZ (2000). Changes in plant species diversity and productivity along gradients of precipitation and elevation in the Xilin River Basin, Inner Mongolia. Acta Phytoecologica Sinica, 24, 667-673. [白永飞, 李凌浩, 王其兵, 张丽霞, 张炎, 陈佐忠 (2000). 锡林河流域草原群落植物多样性和初 级生产力沿水热梯度变化的样带研究. 植物生态学报, 24, 667-673.]

Cai XB, Zhang YQ, Shao W (2007). Degradation and mechanism of grassland of North Tibet alpine prairie. Soil, 39, 855-858. [蔡晓布, 张永青, 邵伟 (2007). 藏北高寒草 原草地退化及其驱动力分析. 土壤, 39, 855-858.]

Chen LL, Shi JJ, Wang YL, Ma YS, Dong QM, Hou XK (2016). Study on different degraded degrees grassland community structure characteristics of the alpine area. Acta Agrectir Sinica, 24, 210-213. [陈乐乐, 施建军, 王 彦龙, 马玉寿, 董全民, 侯宪宽 (2016). 高寒地区不同 退化程度草地群落结构特征研究. 草地学报, 24 , 210-213.]

Dong XB, Zhang XS (2005). View on the grassland in China. Green Economy, (10), 70-73. [董孝斌, 张新时 (2005). 我国草地的发展观. 生态经济, (10), 70-73.]

Gao YZ, Han XG, Wang SP (2004). The effects of grazing on grassland soils. Acta Ecologica Sinica, 24, 790-797. [高英 志, 韩兴国, 汪诗平 (2004). 放牧对草原土壤的影响. 生态学报, 24, 790-797.]

Gu YR, Zhang GF, Meng L (2005). Drought resistance of four forage species at seedling under water stress. Journal of Sichuan Grassland, (4), 4-7. [谷燕蓉, 张国芳, 孟林 (2005). 四种牧草幼苗对水分胁迫的相应及其抗旱性. 四川草原, (4), 4-7.]

He JS, Fang JY, Ma KP, Huang JH (2003). Biodiversity and ecosystem productivity: Why is there a discrepancy in the relationship between experimental and natural ecosystems? Acta Phytoecologica Sinica, 27, 835-843. [贺金生, 方精云, 马克平, 黄建辉 (2003). 生物多样性与生态系 统生产力: 为什么野外观测和受控实验结果不一致? 植物生态学报, 27, 835-843.]

Hou JT, Cheng ZJ (1999). Application and analytical strategies of structure equation modelling. Exploration of Psychology, 19, 54-59. [侯杰泰, 成子娟 (1999). 结构方程模型 的应用及分析策略. 心理学探新, 19, 54-59.]

Kong FZ, Yu RC, Xu ZJ, Zhou MJ (2012). Application of excel in calculation of biodiversity indices. Marine Sciences, 36(4), 57-62. [孔凡洲, 于仁成, 徐子钧, 周名江 (2012). 应用Excel软件计算生物多样性指数. 海洋科学, 36(4), 57-62.]

Li L, Liu W (2011). Relationship between plant functional groups, species richness and community's productivity in degraded grassland. Acta Agrectir Sinica, 19, 917-921. [李 里, 刘伟 (2011). 退化草地植物功能群和物种丰富度与 群落生产力关系的研究. 草地学报, 19, 917-921.]

Li MS (2000). Countermeasures for environmental protection in the Qinghai-Tibet Plateau. Resources Science, 22(4), 78-82. [李明森 (2000). 青藏高原环境保护对策. 资源 科学, 22(4), 78-82.]

Lin HL, Hou FJ, Ren JZ (2008). Evaluation of indicators of grazing trampling intensity. Acta Prataculturae Sinica, 17(1)，85-92. [林慧龙，侯扶江，任继周 (2008). 放牧家 畜的践踏强度指标探讨. 草业学报, 17(1), 85-92.]

Liu W, Wang QJ, Wang X, Zhou L, Li YF, Li FJ (1999). Ecological process of forming "black soil-type" degraded grassland. Acta Agrestia Sinica, 7, 301-305. [刘伟, 王启 基, 王溪, 周立, 李有福, 李发吉 (1999). 高寒草甸“黑 土型”退化草地的成因及生态过程. 草地学报, 7 , 301-305.]

Liu XN, Sun JL, Zhang DG, Pu XP, Xu GP (2008). A study on the community structure and plant diversity of alpine meadow under different degrees of degradation in the Eastern Qilian Mountains. Acta Prataculturae Sinica, 17(4), 1-11. [柳小妮, 孙九林, 张德罡, 蒲小鹏, 徐广平 (2008). 东祁连山不同退化阶段高寒草甸群落结构与植 物多样性特征研究, 草业学报, 17 (4), 1-11.]

Liu XQ, Wu QH, Li HQ, Mao SJ, Li YN (2013). A comparison of the vegetation/soil carbon density and net ecosystem $\mathrm{CO}_{2}$ exchange of alpine meadow with different enclosure durations. Journal of Glaciology and Geocryology, 35, 848-856. [刘晓琴, 吴启华, 李红琴, 毛绍娟, 李英年 (2013). 不同封育年限高寒草甸植被/土壤碳密度及净 生态系统 $\mathrm{CO}_{2}$ 交换量的比较. 冰川冻土, 35, 848-856.]

Long Y, Meng FD, Wang CS, Bai L, Zhong Y, Wang SP (2015). Above- and below-ground biomass distribution of main alpine meadow plants and impact of degradation on root/shoot ratio and root area. Guihaia, 35, 532-538. [龙 毅, 孟凡栋, 王常顺, 白玲, 钟扬, 汪诗平 (2015). 高寒 草甸主要植物地上地下生物量分布及退化对根冠比和 根系表面积的影响. 广西植物, 35, 532-538.]

Luo YY, Meng QT, Zhang JH, Zhao XY, Qin Y (2014). Species diversity and biomass in relation to soil properties of alpine meadows in the eastern Tibetan Plateau in different degradation stages. Journal of Glaciology and Geocryology, 36, 1298-1305. [罗亚勇, 孟庆涛, 张静辉, 赵学勇, 秦或 (2014). 青藏高原东缘高寒草甸退化过程中植物 群落物种多样性、生产力与土壤特性的关系. 冰川冻土, 36, 1298-1305.]

Luo YY, Zhang Y, Zhang JH, Ka ZJ, Shang LY, Wang SY (2012). Soil stiochiometry characteristics among alpine meadows of different degradation stages in Maqu County. Chinese Journal of Ecology, 31, 254-260. [罗亚勇, 张宇, 张静辉, 卡召加, 尚伦宇, 王少影 (2012). 不同退化阶 段高寒草甸土壤化学计量特征. 生态学杂志, 31 ,

www.plant-ecology.com 
254-260.]

Mao F, Zhang YH, Hou YY, Tang SH, Lu ZG, Zhang JH (2008). Dynamic assessment of grassland degradation in Naqu of northern Tibet. Chinese Journal of Applied Ecology, 19，278-284. [毛飞, 张艳红, 侯英雨, 唐世浩, 卢 志光, 张佳华 (2008). 藏北那曲地区草地退化动态评 价. 应用生态学报, 19, 278-284.]

Niu KC, Luo YJ, Choler P, Du GZ (2008). The role of biomass allocation strategy in diversity loss due to fertilization. $B a$ sic and Applied Ecology, 9, 485-493.

Qi B, Zhang DG, Ding LL, Zhang L, Wang X, Yang YH (2005). Properties of plant community diversity of degraded alpine arid grasslands. Journal of Gansu Agricultural University, 40, 626-631. [祁彪, 张德罡, 丁玲玲, 张力, 汪胥, 杨予海 (2005). 退化高寒干旱草地植物群 落多样性特征. 甘肃农业大学学报, 40, 626-631.]

Ren QJ, Cui XL, Zhao BB (2008). Effects of grazing impact on community structure and productivity in an alpine meadow. Acta Prataculturae Sinica, 17(6), 134-140. [仁 青吉, 崔现亮, 赵涁涁 (2008). 放牧对高寒草甸植物群 落结构及生产力的影响. 草业学报, 17(6), 134-140.]

Sala OE, Oesterheld M, León RJC, Soriano A (1986). Grazing effects upon plant community structure in subhumid grasslands of Argentina. Vegetatio, 67, 27-32.

Sheng L, Wang YL (2010). Characteristics variation of soil nutrition in different degraded degree alpine meadow in Dawu region of Guoluo prefecture. Chinese Qinghai Journal of Animal and Veterinary Sciences, 40(4), 4-6. [盛丽, 王彦龙 (2010). 果洛大武地区不同退化梯度下 高寒草甸土壤养分特征变化. 青海畜牧兽医杂志, 40(4), 4-6.]

Studies on the Development of Agriculture and Animal Husbandry Industry with Characteristics of Tibet Autonomous Region Group (2003). Studies on the development of agriculture and animal husbandry industry with characteristics of Tibet Autonomous Region. Journal of China Agricultural Resources and Regional Planning, 24(6), 8-12. [西藏自治区农牧业特色产业发展研究课题组 (2003). 西藏自治区农牧业特色产业发展研究. 中国农业资源 与区划, 24(6), 8-12.]

Wang CT, Long RJ, Wang QL, Cao GM, Shi JJ, Du YG (2008). Response of plant diversity and productivity to soil response changing under grazing disturbance on an alpine meadow. Acta Ecologica Sinica, 28, 4144-4152. [王长庭, 龙瑞军, 王启兰, 曹广民, 施建军, 杜岩功 (2008). 放 牧扰动下高寒草甸植物多样性、生产力对土壤养分条件 变化的响应. 生态学报, 28, 4144-4152.]

Wang DL, Lü XL, Luo WD (1996). Analysis to effects of different grazing density on characteristics of rangeland vegetation. Acta Prataculturae Sinica, 5(3), 28-33. [王德 利, 吕新龙, 罗卫东 (1996). 不同放牧密度对草原植被 特征的影响分析. 草业学报, 5(3), 28-33.]
Wang GX, Shen YP, Cheng GD (2000). Eco-environmental changes and causal analysis in the source regions of the Yellow River. Journal of Glaciology and Geocryology, 22, 200-205. [王根绪, 沈永平, 程国栋 (2000). 黄河源区 生态环境变化与成因分析. 冰川冻土, 22, 200-205.]

Wang QL, Wang CT, Du YG, Cao GM (2008). Grazing impact on soil microbial biomass carbon and relationships with soil environment in alpine Kobresia meadow. Acta Prataculturae Sinica, 17(2), 39-46. [王启兰, 王长庭, 杜岩 功, 曹广民 (2008). 放牧对高寒嵩草草甸土壤微生物量 碳的影响及其与土壤环境的关系. 草业学报, 17(2), 39-46.]

Wang W, Liu ZL, Hao DY, Liang CZ (1996). Research on the restoring succession of the degenerated grassland in Inner Mongolia II. Analysis of the restoring process. Acta Phytoecologica Sinica, 20, 460-471. [王炜, 刘钟龄, 郝敦元, 梁存柱 (1996). 内蒙古草原退化群落恢复演替的研究: II. 恢复演替时间进程的分析. 植物生态学报, 20 , 460-471.]

Wang YX, Cao JM (2007). How to solve the overgrazing problem in Inner Mongolia. Green Economy, (7), 58-64. [王云 霞, 曹建民 (2007). 内蒙古草原过度放牧的解决途径. 生态经济, (7), 58-64.]

Wu ML (2010). Structural Equation Modeling: Operation and Response of AMOS. The University of Chongqing Press, Chongqing. (in Chinese) [吴明隆 (2010). 结构方程模型: AMOS的操作与应用. 重庆大学出版社.]

Yang FY, Zhang YW, Miao YJ, Wei XH (2003). Main limiting factors for deteriorated grasslands vegetation restoration of Northern Tibet Plateau. Bulletin of Soil and Water Conservation, 23(4), 17-20. [杨富裕, 张蕴微, 苗彦军, 魏学 红 (2003). 藏北高寒退化草地植被恢复过程的障碍因 子初探. 水土保持通报, 23(4), 17-20.]

Zhang GS, Li L (1999). Effects of climatic changes of South Qinghai Plateau on the alpine meadow. Acta Prataculturae Sinica, 8(3), 1-10. [张国胜, 李林 (1999). 青南高原气候 变化及其对高寒草甸牧草生长影响的研究. 草业学报, $8(3), 1-10$.]

Zhang J, Zhao H, Zhang T, Zhao X, Drake S (2005). Community succession along a chronosequence of vegetation restoration on sand dunes in Horqin Sandy Land. Journal of Arid Environments, 62, 555-566.

Zhang JP, Chen XH, Zou XY, Ji HL, Du J, Cao ZJ, Fu XF (2001). The eco-environmental problems and its countermeasures in Tibet. Journal of Mountain Science, 19, 81-86. [张建平, 陈学华, 邹学勇, 靳鹤龄, 杜杰, 曹宗 杰, 付雪峰 (2001). 西藏自治区生态环境问题及对策. 山地学报, 19, 81-86.]

Zhao CZ, Long RJ, Ma YH, Ji SZ (2005). The impact of the institution of grassland property right on overgrazing-A case from Hongshiwo countryside, Sunan County, Gansu. Acta Prataculturae Sinica, 14(1), 1-5. [赵成章, 龙瑞军, 
马永欢, 吉生柱 (2005). 草地产权制度对草地超载过牧 的影响一以肃南县红石窝乡的调查为例. 草业学报, 14(1), 1-5.]

Zheng W, Dong QM, Li SX, Li HT, Liu Y, Yang SH (2012). Impact of grazing intensities on community biodiversity and productivity of alpine grassland in Qinghai Lake Region. Acta Agrestia Sinica, 20, 1033-1038. [郑伟, 董全 民, 李世雄, 李红涛, 刘玉, 杨时海 (2012). 放牧强度 对环青海湖高寒草原群落物种多样性和生产力的影响. 草地学报, 20, 1033-1038.]

Zhong XH (2005). Pay close attention to an issue at home and abroad academic circles all along: Research of the Qinghai-Tibet Plateau. Journal of Mountain Science, 23, 257-259. [钟祥浩 (2005). 国内外学术界一直关注的问 题: 青藏高原研究. 山地学报, 23, 257-259.]

Zhou HK, Zhao XQ, Zhou Li, Liu W, Li YN, Tang YH (2005). A study on correlations between vegetation degradation and soil degradation in the alpine meadow of the Qinghai-Tibetan Plateau. Acta Prataculturae Sinica, 14(3), 31-40. [周华坤, 赵新全, 周立, 刘伟, 李英年, 唐艳鸿 (2005). 青藏高原高寒草甸的植被退化与土壤退化特征 研究. 草业学报, 14(3), 31-40.]

Zhu JT (2016). Effects of experimental warming on plant phenology in Xizang alpine meadow. Chinese Journal of Plant Ecology, 40, 1028-1036. [朱军涛 (2016). 实验增
温对藏北高寒草甸植物物候的影响. 植物生态学报, 40 , 1028-1036.]

Zong N, Shi PL, Niu B, Jiang J, Song MH, Zhang XZ, He YT (2010). Effects of nitrogen and phosphorous fertilization on community structure and productivity of degraded alpine meadows in northern Tibet, China. Chinese Journal of Applied Ecology, 25, 3458-3468. [宗宁, 石培礼, 牛 生, 蒋婧, 宋明华, 张宪洲, 何永涛 (2010). 氮磷配施 对藏北退化高寒草甸群落结构和生产力的影响. 应用 生态学报, 25, 3458-3468.]

Zou XY, Dong GR, Li S, Dong YX, Yang P, Ji HL, Zhang CL, Cheng H (2003). Desertification and its prevention and control strategy in Tibet. Journal of Natural Disasters, 17-24. [邹学勇, 董光荣, 李森, 董玉祥, 杨萍, 靳鹤龄, 张春来, 程宏 (2003). 西藏荒漠化及其防治战略. 自然 灾害学报, 12, 17-24.]

Zuo XA, Zhao XY, Zhao HL, Li YQ, Guo ZR, Zhao YP (2007). Changes of species diversity and productivity in relation to soil properties in sandy grassland in Horqin Sand Land. Environmental Science, 28, 945-951. [左小安, 赵学勇, 赵哈林, 李玉强, 郭轶瑞, 赵玉萍 (2007). 科 尔沁沙质草地群落物种多样性、生产力与土壤特性的关 系. 环境科学, 28, 945-951.]

责任编委: 储诚进 责任编辑: 王 葳

\section{附件I 基于熵权法的综合评价}

\section{Appendix I Comprehensive evaluation based on Entropy Method}

\section{1 土地退化评价指标的确定}

依据邱秋兰(2012)的文献检索结果，对土地退化进行评价的指标共计 83 个，大致可以分为植被、气候、土壤、社会经济、 地形地貌及生物 6 类，其中土壤类指标较多，而且植被与社会经济指标所占比例也不少(附件表 1; 邱秋兰, 2012)。

附件表1 土地退化中文指标分类(邱秋兰, 2012)

Appendix table 1 Land degradation index classification in China (Qiu, 2012)

\begin{tabular}{|c|c|c|}
\hline $\begin{array}{l}\text { 指标分类 } \\
\text { Index classification }\end{array}$ & $\begin{array}{l}\text { 指标个数 } \\
\text { Number of indexes }\end{array}$ & 指标 Indexes \\
\hline 土壤 Soil & 41 & $\begin{array}{l}\text { 土壤质地、土层厚度、含水量、团粒结构稳定性等 Soil texture, soil thickness, water content, and } \\
\text { stability of aggregates, etc. }\end{array}$ \\
\hline 植被 Vegetation & 11 & $\begin{array}{l}\text { 植被盖度、植被种类、植被均匀度指数、根系深度等 Vegetation cover, vegetation species, vegetation } \\
\text { Pielou evenness index, and root depth, etc. }\end{array}$ \\
\hline 社会经济 Social economy & 11 & $\begin{array}{l}\text { 经济收入水平(农民收入、消费水平)、人口数量等 Economic income level (farmer's income, con- } \\
\text { sumption level) and population, etc. }\end{array}$ \\
\hline 气候 Climate & 7 & $\begin{array}{l}\text { 降水量、蒸发量、风速、平均气温、湿润指数等 Precipitation, evaporation, wind speed, average } \\
\text { temperature, and wetting index, etc. }\end{array}$ \\
\hline 生物 Biology & 7 & $\begin{array}{l}\text { 生物量、生物多样性指数、群落类型、种群优势度 Biomass, biodiversity index, community type, and } \\
\text { population dominance }\end{array}$ \\
\hline 地形地貌 Topography & 6 & $\begin{array}{l}\text { 坡度、坡向、沟谷密度、地貌类型、海拔高度 Slope, slope direction, valley density, landform type, and } \\
\text { altitude }\end{array}$ \\
\hline
\end{tabular}

其中频次分析结果表明: 应用频次最高的 4 个指标分别为植被盖度、有机质含量、经济收入水平及坡度，频次分别为 116 、 48、43 和 42 (附件表 2; 邱秋兰, 2012)。在以上分析基础上, 参考以往相关研究(周华坤等, 2003; 毛飞等, 2008), 并结合本研 究的数据获取情况, 本文在评价藏北高寒草甸退化过程中选取的评价指标为: 群落总盖度、高山嵩草盖度、土壤碳氮比、地 上生物量、地下生物量及土壤砾石比等 6 个指标。

www.plant-ecology.com 
附件表2 土地退化中文指标应用频次统计(邱秋兰, 2012)

Appendix table 2 Land degradation index of application frequency statistics (Qiu, 2012)

\begin{tabular}{|c|c|c|}
\hline $\begin{array}{l}\text { 频次 } \\
\text { Frequency }\end{array}$ & $\begin{array}{l}\text { 指标个数 } \\
\text { Number } \\
\text { indexes }\end{array}$ & of 指标 Indexes \\
\hline$>40$ & 41 & 植被盖度、经济收入水平、坡度、有机质含量 Vegetation cover, economic income level, slope, organic matter content \\
\hline $30-39$ & 11 & $\begin{array}{l}\text { 土壤质地、氮、磷和钾元素含量、含水量、土地利用类型 Soil texture, nitrogen, phosphorus and potassium content, water content, land } \\
\text { use type }\end{array}$ \\
\hline $20-29$ & 11 & 生产力、降水量、生物多样性、生物量、地貌类型 Productivity, precipitation, biodiversity, biomass, landform type \\
\hline $10-19$ & 7 & 土壤类型、覆沙盖度、土层厚度、风速、蒸发量 Soil type, cover sand cover, soil thickness, wind speed, evaporation \\
\hline$<10$ & 7 & 土壤容重、土壤侵蚀模数、电导率、径流量、结皮厚度 Soil bulk density, soil erosion modulus, conductivity, runoff, crust thickness \\
\hline
\end{tabular}

\section{2 综合评价}

熵权法是一种客观赋权法, 它充分利用了原始数据提供的信息, 在实践应用中是一种简单可行的科学方法。值得注意的 是, 由于计算中要用到对数函数, 对数据有一定的限制, 要求各项数据大于 0 (肖香玉, 2003)。本文在借鉴以往研究成果基础 上将高寒草甸退化程度分为轻度退化、中度退化、重度退化、极度退化(周华坤等, 2005; 沈渭寿等, 2006; 毛飞等, 2008; 罗亚 勇等, 2014), 结合藏北高寒草甸退化的分级及综合评价的指标选取情况, 依据熵权法综合评价得出不同退化程度的得分, 由 对照处理到极度退化处理评价得分分别是 70.52、62.14、45.24、29.4 和 22.55, 可以发现随着退化程度的不断加深综合评价 得分持续下降。

\section{参考文献}

Qiu QL (2012). Assessment of Degraded Land in the Heihe River Basin, Arid Northwestern China. Master degree dissertation, Shandong Normal University, Jinan. [邱秋兰 (2012). 西北干旱区黑河流域土地退化评价研究, 硕士学位论文, 山东师范大学, 济南.]

Shen WS, Cao XZ, Shen FY (2006). Classification and grading of land degradation in China. Journal of Ecology and Rural Environment, 22(4), 88-93. [沈渭寿, 曹学章, 沈发云 (2006). 中国土地退化的分类与分级. 生态与农村环境学报, 22(4), 88-93.]

Xiao XY (2003). Study on the Appraisal of Enterprise Competitiveness. Master degree dissertation, Jiangxi University of Finance and Economics, Nanchang, Jiangxi. [肖香玉 (2003). 企业竞争力评价研究. 硕士学位论文, 江西财经大学, 江西南昌.]

Zhou HK, Zhou L, Zhao XQ, Liu W, Yan ZL, Shi Y (2003). Degradation process and integrated treatment of "black soil beach" grassland in the source regions of Yangtze and Yellow Rivers. Chinese Journal of Ecology, 22(5), 51-55. [周华坤, 周立, 赵新 全, 刘伟, 严作良, 师燕 (2003). 江河源区“黑土滩”型退化草场的形成过程与综合治理. 生态学杂志, 22(5), 51-55.] 